\title{
PEMBIMBINGAN PEMBUATAN STANDAR OPERASIONAL PROSEDUR (SOP) PADA USAHA BATU BATA DI KOTA BATAM
}

\author{
Nur Elfi Husda*1, Sri Zetli ${ }^{2}$, Narti Eka Putria ${ }^{3}$, Ummi Kalsum Harahap ${ }^{4}$, Miftach Rizqillah $^{5}$ \\ Universitas Putera Batam; Batam, Kepulauan Riau \\ Program Studi Manajemen, Fakultas Ilmu Sosial dan Humaniora \\ e-mail: *nurelfi@puterabatam.ac.id
}

Informasi Artikel
Diterima Redaksi: 29 August 2019
Revisi Akhir: 03 Sept 2019
Diterbitkan Online: 27 Sept 2019
Kata Kunci
SOP, Batu Bata, Home Industry

Korespondensi

No. HP:

\begin{abstract}
Usaha batu bata merupakan industri yang cukup lama ada di Kota Batam, yang diperkirakan sudah ada sejak tahun 1898 dan saat itu bersaing ketat dengan produksi batu bata di negara Singapura. Salah satu tempat usaha batu bata adalah di Kelurahan Tanjung Piayu, Kecamatan Sei Beduk, Batam. hal ini dikarenakan di lokasi ini banyak terdapat lahan kosong yang mengandung tanah liat yang baik untuk dasar pembuatan batu bata. Usaha batu bata yang ada sebagian besar dilakukan oleh home industry dan usaha keluarga. Proses yang dilakukan oleh mitra pengabdian adalah dengan cara manual dan belum ada panduan standar untuk melaksanakan proses pengerjaan batu bata sehingga terkadang pekerja menjadi kelelahan dan jika ada kesalahan, pekerja akan kesulitan menemukan pada tahap mana kesalahan dilakukan. Hal ini karena tidak adanya Standar Operasional Prosedur (SOP) sebagai panduan dalam bekerja. Untuk itu tim pengabdian melaksanakan pembimbingan dan pelatihan tentang SOP agar pemilik dan pekerja dapat memahami dan dapat membuat prosedur dari setiap tahapan-tahapan pekerjaan yang dilakukan. Hasil pelaksanaan pengabdian yang sudah dilakukan adalah pemilik dan pekerja menjadi memahami langkah pembuatan SOP serta telah adanya beberapa SOP dari tahapan pelaksanaan pekerjaan pembuatan batu bata dari awal sampai dengan akhir yaitu sampai batu bata dikirimkan kepada suplier.
\end{abstract}

\section{PENDAHULUAN}

Usaha batu bata merupakan industri yang cukup lama sudah ada di Kota Batam yang diperkirakan sudah sejak tahun 1898 yang bersaing ketat dengan produksi batu bata di negara Singapura. Hingga saat ini industri batu bata tetap memberikan kontribusi bagi sektor ekonomi di Kota Batam. Salah satu tempat usaha batu bata yang banyak di Kota Batam berada di Kelurahan Tanjung Piayu dikarenakan di lokasi ini banyak terdapat lahan kosong yang mengandung tanah liat yang baik sebagai dasar bagi pembuatan batu bata. Adapun luas wilayah kelurahan Tanjung Piayu menurut data (BPS, 2015) adalah $28.295 \mathrm{Km}^{2}$.

Proses pembuatan batu bata yang dilakukan oleh banyak industri batu bata di kelurahan Tanjung Piayu, termasuk pada industri batu bata Heri (mitra 1) dan Yasin (Mitra 2) dilakukan melalui beberapa tahapan proses. Adapun tahapan prosesnya adalah penggalian bahan mentah, pencapuran bahan baku hingga menghasilkan campuran batu bata, percetakan batu bata, pengeringan dan pembakaran. Informasi yang didapat dari mitra bahwa masih sering terjadi kesalahan saat melakukan pekerjaan yang mana berpengaruh terhadap keselamatan pekerja dan output produksi batu bata. Hal tersebut dikarenakan masih banyaknya proses yang dilakukan secara manual, selain itu tidak adanya panduan berupa Standar Operasional Prosedur (SOP) kerja dalam melakukan tahapan kerja membuat pekerja bekerja hanya berdasarkan tenaga yang dimiliki dan waktu pekerjaannya. 
Seperti pada saat pengangkatan, baik pengangkatan material ataupun pengangkatan batu bata yang sudah siap dicetak, disini pekerja melakukan pengangkatan berdasarkan kekuatan yang dimiliki tanpa mempertimbangkan kapasitas angkatnya sehingga dari wawancara yang dilakukan dengan beberapa pekerja pada mitra 1 ataupun mitra 2, banyak pekerja mengeluh kelelahan. Selain berpengaruh terhadap pekerjanya, proses pekerjaan yang salah juga berpengaruh terhadap hasil pekerjaannya sehingga sangat diperlukan SOP dalam bekerja.

Dalam menjalankan kegiatan operasional suatu organisasi diperlukan panduan yang dapat digunakan untuk memastikan kegiatan operasional organisasi tersebut dapat berjalan dengan lancar yang disebut dengan Standar Operational Prosedur (SOP) [1]. Menurut fungsi SOP itu sendiri menurut [2] adalah (1) Memperlancar tugas unit kerja sesuai dengan pernyataan [3] bahwa prinsip prosedur kerja berpengaruh terhadap kinerja pegawai, (2) Dapat dijadikan dasar hukum jika terjadi penyimpangan, (3) Mudah dilacak apabila diketahui hambatanhambatannya, (4) mengarahkan unit kerja agar disiplin dalam bekerja serta (4) dapat dijadikan pedoman dalam melaksanakan pekerjaan yang rutin. Dengan adanya SOP akan sangat membantu organisasi agar dapat melakukan pekerjaan dengan efektif dan efisien [4]

Metode pengolahan bahan baku batu bata oleh mitra 1 dan mitra 2 sudah dilakukan menggunakan proses semi mekanis dengan menggunakan mesin pengaduk, seperti pada gambar 1 dimana produktifitas batu bata mulai dari 90.000pcs sampai dengan 300.000pcs buah perbulan pada kedua mitra.
Setelah batu bata dicetak maka batu bata akan disusun dibeberapa tempat untuk lanjut keproses pengeringan.

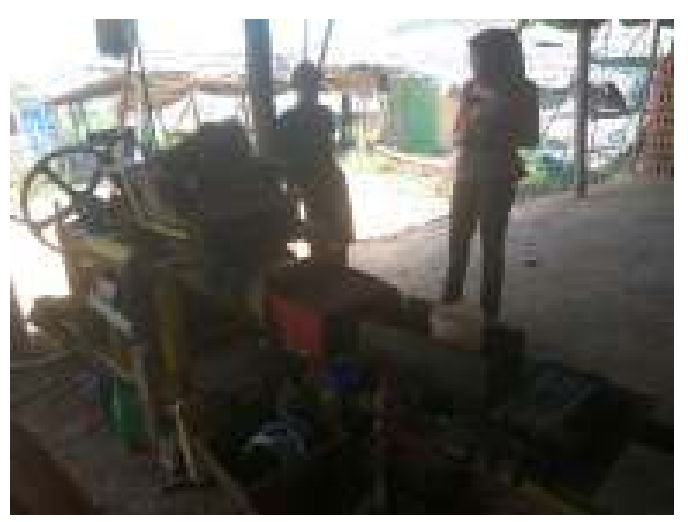

Gambar 1. Metode Pengolahan Bahan Baku Batu Bata dengan Mesin Pengaduk

Proses pengeringan dilakukan secara manual dengan memanfaatkan alam yaitu panas dan angin, semakin panas suhu lingkungan maka akan semakin cepat proses pengeringan dan sebaliknya semakin turun suhu lingkungan disebabkan karena hujan maka semakin lama proses pengeringan. Proses pengeringan membutuhkan waktu yang cukup lama, tergantung dengan cuaca. Paling cepat proses pengeringan membutuhkan waktu 30 hari. Proses pembakaran juga dilakukan secara manual yaitu dengan menggunakan kayu panggang. Pada proses pembakaran dibutuhkan banyak kayu untuk batu bisa matang dengan sempurna. Proses pembakaran membutuhkan waktu paling sedikit 48 jam (2 hari). Pada proses pembakaran, batu bata disusun disebuah tungku seperti terlihat pada Gambar 2. 


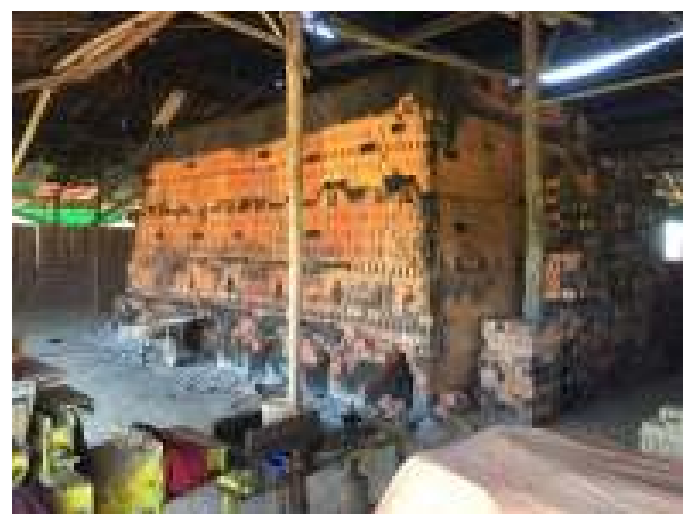

Gambar 2. Batu Bata Setelah Dibakar

Tersusun di Tungku Pembakaran

Adapun tujuan dari kegiatan pengabdian ini adalah untuk membuka kesempatan kepada kelompok usaha batu bata dalam mengembangkan usaha batu bata sebagai ekonomi produktif dan berkelanjutan, selain dari itu kegiatan pengabdian ini juga bertujuan untuk melakukan pelatihan dan pemahaman tentang bagaimana membuat pedoman berupa standar operasional prosedur dari tahapan-tahapan kerja yang dilakukan.

\section{METODE}

Metode pelaksanaan kegiatan pengabdian kepada kedua mitra dari Program Kemitraan Masyarakat dengan mitra usaha batu bata yang dilaksanakan di Kelurahan Tanjung Piayu, Kecamatan Sei Beduk, Batam dilakukan dengan beberapa tahapan yaitu:

\section{a. Survei}

Tahap survei dilakukan dengan menghubungi dan melihat langsung untuk mendapatkan gambaran tentang usaha batu bata yang dilakukan kedua mitra, dengan tujuan untuk mencari permasalahan mitra yang berkaitan dengan tahapan pelaksanaan prosedur kerja yang dilakukan oleh kedua mitra untuk mendapatkan gambaran tentan standar operasional prosedur yang akan dikembangkan. b. Persiapan

Tahap persiapan dilakukan oleh tim pengabdian bersama kedua mitra usaha batu bata berupa menyusun dan menyepakati rencana kegiatan, pendataan usaha serta persiapan surat persetujuan dari kedua mitra pengabdian.

c. Pelaksanaan

Tahap pelaksanaan dilakukan dengan melaksanakan pelatihan dan pemahaman serta bimbingan berupa pembuatan Standar Operasional (SOP) kerja yaitu bagaimana cara membuat prosedur kerja mulai dari tahapan awal pengerjaan batu bata yaitu penggalian material batu bata sampai dengan batu bata tersebut siap untuk dibakar. Setiap pengerjaan akan dibuatkan SOP kerja sehingga nantinya jika kualitas batu bata tidak sesuai denga kualitas yang diinginkan maka mitra ataupun pekerja akan mengetahu secara langsung dibagian mana saja kesalahan tersebut terjadi dapat diperbaiki sesegera mungkin.

d. Evaluasi

Tahap ini dilakukan untuk menilai hasil yang dicapai oleh peserta pelatihan, evaluasi dilakukan dengan mengumpulkan data berupa pemahaman yang diperoleh dari kegiatan pelatihan yang akan dilaksanakan. Tahapan evaluasi dilakukan setelah pelaksanaan dilakukan dengan cara membandingkan antara sebelum diberikan pelatihan dan bimbingan serta setelah diberi pelatihan dan bimbingan, salah satunya adalah tentang ketepatan waktu kerja.

\section{HASIL DAN PEMBAHASAN}

Hasil dari pelaksanaan kegiatan bimbingan dan pelatihan pembuatan SOP kerja pada usaha batu bata pada kedua mitra yang berada di Kelurahan Tanjung Piayu Batam dilaksanakan dengan tahapan 
kegiatan berupa survei, persiapan, pelaksanaan dan evaluasi kegiatan.

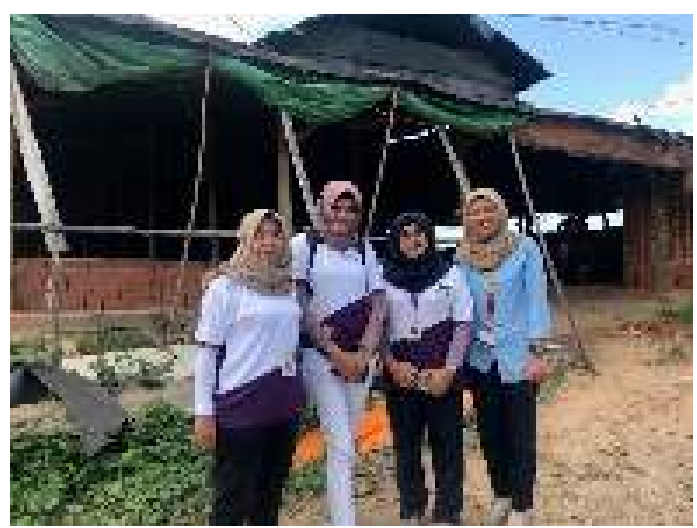

Gambar 3. Kunjungan tim pengabdian ke

Lokasi usaha mitra batu bata

Pelatihan dilakukan dengan mengumpulkan pemilik dan pekerja dari kedua mitra yang kemudian dilaksanakan pelatihan pembuatan SOP dengan materi tentang apa yang dimaksud dengan SOP, langkah pembuatan SOP adalah sebagai berikut:

1. Membuat susunan kerja yang akan dibuatkan SOP nya

2. Merencanakan alur proses dengan format SOP yang akan dibuat serta bagaimana SOP tersebut dapat diakses

3. Melakukan wawancara kepada setiap pekerja, dimana hal tersebut bertujuan untuk mengetahui bagaimana pekerja tersebut bekerja

4. Menulis SOP yang kemudian dibahas kembali dengan pihak-pihak terkait agar jika masih ada celah dari SOP yang akan ditulus dapat disesuaikan kembali

5. SOP yang sudah ditulis dan disepakati kemudian disosialisasikan kepada pekerja terkait

6. Melakukan evaluasi SOP apakah SOP tersebut sudah sesuai dengan yang diharapkan atau ada yang perlu

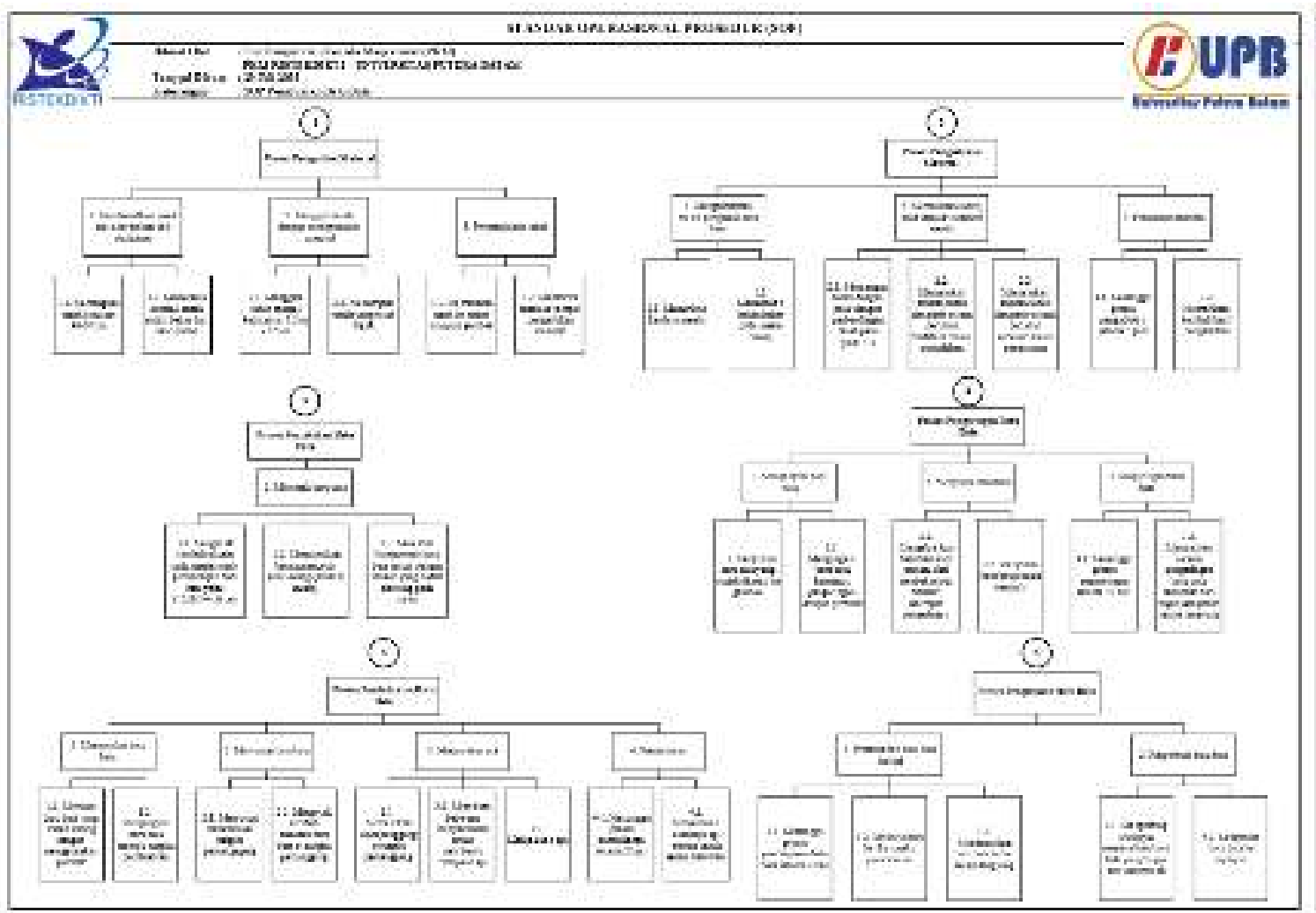

Gambar 4. SOP Kerja Batu Bata

manfaat dari SOP, fungsi dari SOP, serta langkah-langkah pembuatan SOP kerja pembuatan batu bata. Adapun langkah- ditambahkan dan dikurangi.

Pembimbingan Pembuatan SOP 


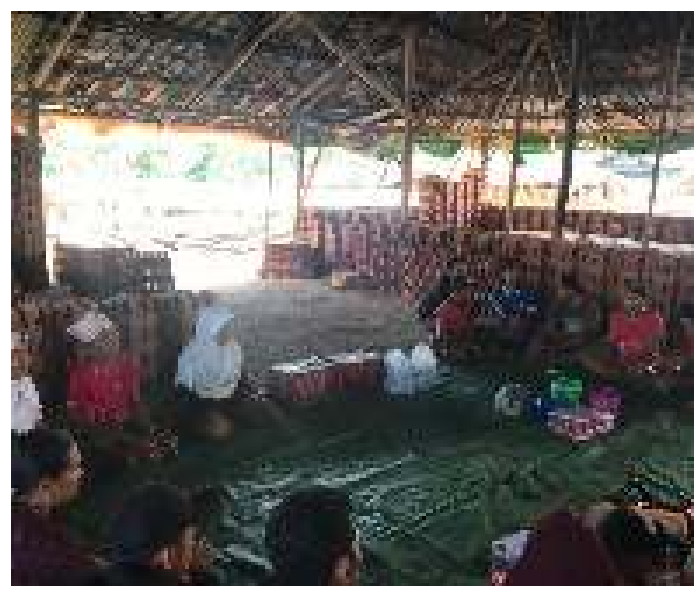

Gambar 5. Pelaksanaan Bimbingan dan Pelatihan Pembuatan SOP Kerja

Setelah pelaksanaan kegiatan bimbingan dan pelatihan pembuatan SOP dilaksanakan, tim pengabdi melakukan evaluasi kegiatan dan kemudian menuangkan hasil SOP yang sudah disepakati kedua mitra dalam bentuk cetakan untuk kemudian diserahkan kepada kedua mitra.

SOP yang dibuat berdasarkan hasil wawancara dengan pemilik dan pekerja kedua mitra terdiri dari 6 SOP yaitu:

\section{Proses Penggalian Material}

Proses ini dilakukan dalam 9 langkah mulai dari membersihkan tanah dari akar pohon dan dedaunan sampai dengan proses terakhir yaitu membawa tanah kerempat pengadukkan material.

2. Proses Pengadukan Material

Proses dilakukan dimulai dari menghidupkan mesin pengaduk batu bata sampai dengan proses memeriksa kembali hasil pengadukan yang semuanya dilakukan dalam 10 langkah

3. Proses Pencetakan Batu Bata

Proses dilakuakn dalam 4 langkah yang dimulai dari mencetak batu bata sampai dengan mencetak (memotong) batu bata sesuai dengan ukuran yang sudah disetting pada mesin
4. Proses Pengeringan Batu Bata

Proses dilakukan dalam 9 langkah yang dimulai dengan mengankat batu bata sampai dengan proses terakhir memastikan selama proses pengeringan batu bata terhindar dari hujan dan panas secara langsung

5. Proses Pembakaran Batu Bata

Proses pembakaran dilakukan dalam 13 langkah yang dimulai dari mengangkat batu bata sampai proses terakhir yaitu memastikan besarnya api merata untuk semua batu bata

6. Proses Pengiriman Batu Bata

Proses pengiriman dilakukan dalam 7 langkah yaitu memindahkan batu bata ke lori (truk) sampai dengan proses terakhir mengantar batu bata ke suplier

Keenam SOP yang sudah diselesaikan kemudian dibingkai dan diletakkan di lokasi yang mudah diakses, kemudian di sosialisakan kepada semua pekerja, agar pekerja memiliki panduan dalam bekerja. Dari beberapa penelitian terdahulu terdapat bahwa dengan adanya SOP akan meningkatkan kinerja karyawan [5] demikian juga hasil penelitian yang dilakukan oleh [6] bahwa penerapan SOP dapat meningkatkan kinerja karyawan.

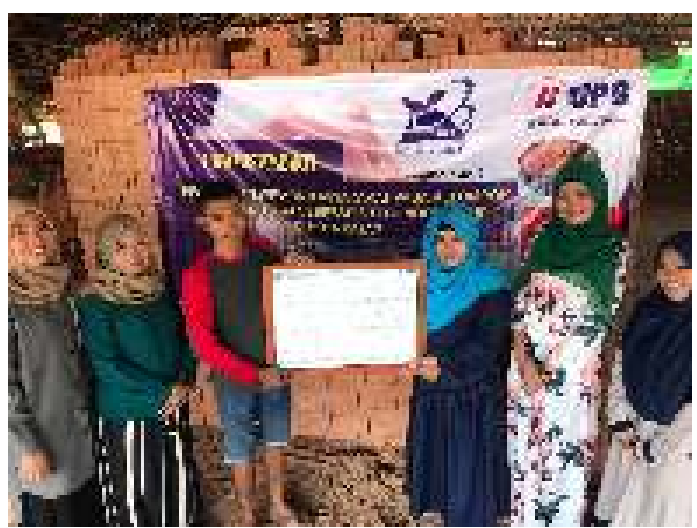

Gambar 6. Serah Terima SOP Kerja Dengan Mitra 1 


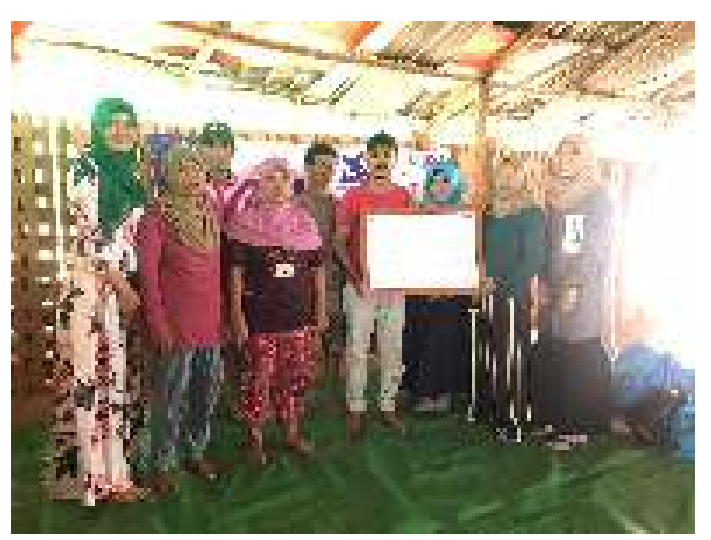

Gambar 7. Serah Terima SOP Kerja Dengan Mitra 2

Setelah SOP diberikan kepada kedua mitra untuk dapat digunakan sebagai panduan dalam bekerja, dan dilakukan wawancara kepada pekerja dari kedua mitra, beberapa minggu setelah menggunakan SOP pekerja kedua mitra mengatakan bahwa SOP sangat membantu pekerja dalam menjalankan pekerjaan sehari-hari hal tersebut sesuai dengan pernyataan [7] bahwa SOP yang dibuat akan memudahkan pekerja dalam menjalankan prosedur yang sama dan dapat menghasilkan produk yang sesuai dengan standarisasi.

\section{KESIMPULAN}

Dari hasil pengabdian kepada masyarakat yang dilakukan pada usaha batu bata di Kelurahan Tanjung Piayu Batam dapat disimpulkan bahwa SOP yang sudah dibuat harus disosialisakan terlebih dahulu serta ditempatkan di tempat yang mudah diakses oleh semua pekerja dan dengan penerapan SOP sebagai panduan kerja akan meningkatkan kinerja pekerja usaha batu bata serta hasil dari produksi batu bata yang sudah dijalankan menggunakan SOP akan menghasilkan produk yang sesuai dengan standarisasi serta akan lebih mempermudah menemukan masalah jika terdapat kendalakendala pada hasil akhir.
Kegiatan bimbingan dan pelatihan pembuatan SOP yang dilakukan pada dua mitra usaha batu bata di Kelurahan Tanjung Piayu, Batam telah berhasil dilakukan dan dipraktekan oleh kedua mitra, namun masih harus dilakukan monitoring dari penggunaan SOP tersebut terhadap pekerja batu bata agar benar-benar memberikan manfaat terutama dalam meningkatkan kualitas produk dan kinerja dari pekerja batu bata.

\section{UCAPAN TERIMA KASIH}

Penulis mengucapkan terima kasih kepada Kementrian Riset Teknologi dan Pendidikan Tinggi (Kemenristekdikti) yang telah memberikan dukungan dana bagi program Program Kemitraan Masyarakat tahun anggaran 2019.

\section{DAFTAR PUSTAKA}

[1]A. Sailendra, Langkah-Langkah Praktis Membuat SOP, Cetakan Pe.

Yogyakarta: Trans Idea Publishing, 2015.

\section{[2]I. P. Hartatik, Buku Praktis}

Pengembangan SDM. Yogyakarta: Laksana, 2014.

[3]I. Chasanah and A. Rustiana, "Economic Education Analysis Journal PENGARUH KEMAMPUAN KERJA, FASILITAS KERJA, DAN PRINSIP PROSEDUR KERJA TERHADAP KINERJA PEGAWAI DI KANTOR KECAMATAN SE KABUPATEN BATANG Info Artikel," Econ. Educ. Anal. J., vol. 6, no. 2, pp. 433-446, 2017.

[4]L. M. Handoko, "Penyusunan Standar Operasional Prosedur Pada Operasional Toko Di Supermarket Ufo (United Fashion Outlet) Surabaya," J. Ilm. Mhs. Manaj., vol. 1, no. 2, pp. 2-6, 2013.

[5]I. Rizal Megantara and A. Endang Prihatini, "Pengaruh Kepemimpinan dan 
Standar Operasional Prosedur Terhadap Kinerja Karyawan Studi Kasus Pada Departemen Housekeeping Hotel Crowne Plaza Semarang," J. Ilmu Adm. Bisnis, vol. 5, no. 3, pp. 226-235, 2016.

[6]Y. A. K. Wardani, "Pengaruh Gaya Kepemimpinan, Standar Operasional Prosedur Dan Turn Over Terhadap Kinerja Karyawan Hotel Everbright Di Surabaya," Branchmarck, vol. 4, no. 3, pp. 11-20, 2018.

[7] S. Vania Winata, "Perancangan Standard Operating Procedure (SOP) Pada Chocolab," J. Manaj. dan Start-Up Bisnis, vol. 1, no. 1, pp. 77-86, 2016. 